\title{
A influência do risco-aventura no processo de coesão das diferentes comunidades do voo livre
}

\author{
Sergio Luiz Gomes de Azevedo * \\ Ney Felippe de Barros Rodrigues Cocchiarale ** \\ Vera Lucia de Menezes Costa ***
}

\begin{abstract}
Resumo: O objetivo deste estudo foi investigar os sentidos do risco como elemento gerador de comunhão entre os praticantes de voo livre. Foram analisados 10 depoimentos, publicados nas revistas Air Time Adventure e Sky News, e no livro Parapente Brasil. Trata-se de uma investigação exploratória com abordagem qualitativa. Partindo destes discursos, analisaram-se os aspectos do risco-aventura que contribuem para o processo de coesão vivenciado no cotidiano de suas práticas. Constatou-se que o risco é um elemento fundamental na formação das comunidades de voo, possibilitando aos indivíduos que enfrentam juntos os mesmos riscos se percebam como pessoas que professam valores semelhantes.
\end{abstract}

Palavras-chave: Voo livre. Assunção de riscos. Valores sociais

\section{INTRODUÇÃO}

A necessidade de aventurar-se, de desvendar novos caminhos e de superar limites sempre esteve presente no imaginário humano. Desde os mais remotos tempos o homem tem se lançado em heróicas empreitadas, motivado inicialmente por um natural instinto de preservação que culminou nas mais espetaculares conquistas da humanidade, consagrando à categoria de heróis destemidos simples

\footnotetext{
* Mestrando do curso de Educação Física e Cultura da Universidade Gama Filho. Grupo de Estudos do Laboratório do Imaginário e das Representações Sociais, sobre Ludicidade Esporte e Lazer (LIRES / LEL). Universidade Gama Filho. Rio de Janeiro, RJ, Brasil. E-mail: sergiomeriti@gmail.com

** Mestrando do curso de Educação Física e Cultura da Universidade Gama Filho. Grupo de Estudos do Laboratório do Imaginário e das Representações Sociais, sobre Ludicidade Esporte e Lazer (LIRES / LEL).

Universidade Gama Filho. Rio de Janeiro, RJ, Brasil. E-mail: neycocchiarale@oi.com.br *** Doutora do Curso de Pós-graduação em Educação Física e Cultura da Universidade Gama Filho. Universidade Gama Filho. Rio de Janeiro, RJ, Brasil. E-mail: veralmc@globo.com
} 
mortais que ousaram mortais que ousaram desafiar os perigos de ambientes considerados sagrados e repletos de mistérios, como o céu, as florestas, os oceanos e as montanhas.

Essa ousadia, esse desejo de conquistar novos espaços, de buscar outros caminhos, de fugir da dura realidade cotidiana, têm se manifestado de forma expressiva em diferentes segmentos sociais da atualidade, como é o caso das inúmeras tribos ${ }^{1}$ de aventureiros que transitam pelas práticas esportivas de risco-aventura ${ }^{2}$.

O risco presente nessas práticas pode caracterizar-se por situações onde o indivíduo enfrenta ambientes imprevisíveis como ar, água, floresta, desertos, entre outros, se dispondo a resultados incertos, como ocorre no voo livre, no paraquedismo, na escalada, no surfe e em muitas outras atividades realizadas na natureza. Nesse ambiente, o risco pode proporcionar prazer, assim como pode vir a ser uma experiência negativa, que resulta em medo, prejuízos físicos ou até mesmo em morte. Levando-se em conta as condições ambientais, a habilidade dos atores, a qualidade e validade dos equipamentos utilizados, pode-se afirmar que o sucesso nessas vivências será determinado pela atitude de cada indivíduo diante das situações de risco enfrentadas.

Na definição de Almeida (2008), risco é a possibilidade de fatalidade ou de lesões de diferentes proporções enfrentadas pelo indivíduo na prática de determinadas atividades.

Por outro lado, como observado por Giddens (2002), o risco se destaca em duas situações distintas: uma limitada às condições oferecidas pelo modo de vida social, e a outra, aos padrões de estilo de vida a que se aderiu. No primeiro caso, o risco é involuntário e indesejado, atingindo indiscriminadamente a todos que vivem em sociedade. No segundo caso, o risco é reservado aos esportes perigosos praticados em ambientes institucionalizados, onde os

\footnotetext{
${ }^{1} T$ Termo utilizado por Maffesoli (2000) quando se refere ao vaivém constante que se estabelece entre a massificação crescente e o desenvolvimento dos microgrupos, dizendo tratar-se de uma tensão fundadora que parece caracterizar a socialidade deste fim de século.

${ }^{2}$ Expressão utilizada por Spink, Aragaki e Alves (2005) no artigo que trata da questão que contrasta esportes radicais e turismo de aventura.
} 
indivíduos, de forma voluntária, decidem colocar em jogo suas próprias vidas.

Segundo Costa (2000), os novos aventureiros dos esportes, confiando no domínio cada vez maior da técnica, valorizam e enfrentam o risco como uma aventura pautada pela subjetividade do lúdico que envolve a atividade. Nesse lúdico, criatividade e prazer caminham juntos.

A existência de um tipo de prazer que se manifesta preferencialmente em situações de vertigem recebe destaque nos estudos de Quinodoz (1995). Neste caso, o indivíduo enfrenta situações de risco com o intuito de provocar em seu próprio corpo agradáveis sensações de angústia e prazer.

A vertigem originária desta espécie de risco é descrita por Caillois (1990) como uma sensação voluptuosa que invade o corpo e, por um breve momento, inflige à consciência lúcida uma espécie de espasmo, de estonteamento que faz a realidade desvanecer-se por alguns instantes.

Esse estonteamento prazeroso, essa busca por sensações agradáveis proporcionadas pela vertigem parecem incidir com frequência sobre as escolhas esportivas dos novos aventureiros, orientando as buscas por diferentes práticas de risco, seja no ar, no mar ou na terra.

Partindo destas diferentes interpretações, pretendemos trazer à tona aspectos esclarecedores a respeito dos sentidos do risco para os praticantes de voo livre. Risco que, nesta perspectiva, se restringe às situações a que cada indivíduo se submete quando enfrenta, de forma voluntária, as imprevisibilidades do espaço aéreo, voando especificamente de asa-delta ou de parapente.

Seguindo este viés, consideraremos voo livre aqueles voos impulsionados por agentes naturais (vento, gravidade e correntes térmicas), que dependam basicamente do equipamento utilizado e da habilidade dos atores envolvidos neste tipo de atividade. Sendo assim, modalidades como paraquedismo, sky surf, wingsuift flying, base 
jump, speedflying, entre outras, apesar de também possibilitarem o voo livre pelos ares, não serão destacadas.

No cenário atual, o voo livre pode ser realizado com objetivos e formas bem variados. Ele pode ser praticado com asa-delta ou parapente, e, dependendo do nível técnico de cada indivíduo, pode propiciar voos de alta, média ou baixa performance. O tipo de voo escolhido vai estar relacionado ao nível de experiência, à habilidade e ao tipo de equipamento utilizado - que, neste caso, deverá estar sempre em sintonia com o objetivo desejado. Ou seja, se o indivíduo pretende concorrer em campeonatos, superar recordes ou até mesmo seus próprios limites, se faz necessária a valorização maior de conhecimentos técnicos e a aquisição de equipamentos adequados a voos mais performáticos. Por outro lado, quando se valoriza uma prática menos competitiva e dentro de níveis de segurança mais controláveis, como é o caso dos voadores iniciantes, o uso de equipamentos menos performáticos passa a ser fundamental para que os riscos sejam mantidos dentro de padrões aceitáveis para a segurança do esporte.

Além dos voadores avançados e dos iniciantes, existem ainda aqueles que, mesmo possuindo experiência para voar em equipamentos mais performáticos, optam por equipamentos mais adequados aos voos de baixa ou média performance, que oferecem melhores condições de controle e, por consequência, garantem voos menos arriscados.

Quanto à estrutura, os dois equipamentos utilizados na prática deste esporte apresentam características bem distintas. A asa-delta é constituída por superfícies aerodinâmicas móveis, fabricadas com alumínio, fibra de carbono e fibra de vidro, revestidas por dacron ${ }^{3}$. Suas manobras dependem do deslocamento do peso do corpo do piloto, que voa dentro de uma espécie de casulo preso a um trapézio posicionado na parte inferior da asa, onde os comandos direcionais são executados. O parapente, também conhecido como paraglider, é controlado a partir de comandos manuais, não apresenta estrutura

\footnotetext{
${ }^{3}$ Tipo de tecido sintético utilizado na fabricação das velas de parapente, asa-delta, barco etc.
} (DICIONÁRIO Náutico, 2009). 
rígida, é composto por um tecido de nylon denominado velame e de um conjunto de linhas resistentes que são ligadas à selete ${ }^{4}$, através dos tirantes ${ }^{5}$ e dos mosquetões . $^{6}$

Diante da variabilidade que o voo livre oferece, da incerteza proporcionada pelas imprevisibilidades do ambiente aéreo, da ousadia de desafiar o espaço voando com os pássaros (AZEVEDO; COSTA, 2008), buscamos investigar neste estudo os sentidos do risco enquanto elemento gerador de comunhão entre os praticantes desse esporte.

\section{Metodologia}

Para nos aproximarmos da real situação vivenciada no universo dos praticantes de voo livre, recorremos a uma investigação exploratória com abordagem qualitativa, onde aspectos relacionados ao risco-aventura de voar por esporte foram abordados como tema principal. $\mathrm{O}$ destaque atribuído a esses aspectos se deu a partir da análise dos discursos retirados dos depoimentos publicados no livro Parapente Brasil: Histórias e aventuras do voo livre ${ }^{7}$ (LOPES et al., 2002) e de entrevistas concedidas por pilotos de asa-delta e de parapente e publicadas nas revistas Air Time Adventure e Sky News ${ }^{8}$, cujo critério de inclusão baseou-se na presença dos temas risco e coesão como geradores de comunhão entre os praticantes de voo livre. A interpretação dos discursos se desenvolveu por meio da Análise de Conteúdo, método de investigação que, de acordo com Bardin (2004), visa compreender criticamente o sentido das

\footnotetext{
${ }^{4}$ Selete é a cadeirinha que se conecta a vela do parapente através dos mosquetões; é o local onde o piloto senta para controlar o equipamento durante o vôo (LOPES et al., 2002).

${ }^{5}$ Tira de nylon que une as linhas da vela do parapente ao mosquetão fixado na selete (LOPES et al., 2002).

${ }^{6} \mathrm{O}$ mosquetão, é um anel metálico que possui um segmento móvel, chamado gatilho, que se abre para permitir a passagem da corda. É um equipamento típico de uso em, por exemplo, escalada, espeleologia e canyoning WIKIPÉDIA, 2009.).

${ }^{7}$ Livro criado pelo piloto de parapente Rodrigo Stulzer Lopes em 2002, a partir de mensagens enviadas por pilotos de asa-delta e de parapente, assinantes da lista de discussão da internet Parapente-Brasil, para o endereço http://listas2.conectiva.com.br/listas/parapente-BR, no período compreendido entre 1997 e 2002.

${ }^{8}$ Revistas de publicação trimestral cujo conteúdo é voltado especificamente para os praticantes de voo livre.
} 
comunicações, seu conteúdo manifesto ou latente, seu significado explícito ou oculto.

Seguindo esta trilha metodológica analisamos 10 depoimentos de 09 voadores, publicados nas revistas e no livro anteriormente citados, sendo 03 praticantes da modalidade asa delta, 04 da modalidade parapente e 02 praticantes de ambas as modalidades. Este quantitativo se justifica pelo fato de termos optado pela utilização do método de saturação discursiva. Segundo Bauer e Gaskell (2002, p.59), a seleção em uma pesquisa qualitativa deve ser um processo cíclico, onde o critério responsável pela finalização deste processo é a saturação: "[...] investigam-se diferentes representações, apenas até que a inclusão de novos estratos não acrescente mais nada de novo". Todos os entrevistados são do sexo masculino e praticam a atividade tanto por lazer como de forma competitiva.

A partir da análise destes depoimentos referenciamos os aspectos que contribuem para o processo de coesão vivenciado no cotidiano dos diferentes grupos que ousam enfrentar os riscos oferecidos pelo ambiente aéreo.

\section{ASPECTOS QUE CONTRIBUEM PARA A COESÃO NO VOO LIVRE}

Em qualquer prática esportiva de risco-aventura, a possibilidade de acidentes é uma realidade entre os praticantes de voo livre. Tanto no voo de asa-delta quanto no de parapente há possibilidades de colisões aéreas ou pousos malsucedidos, gerando consequências imprevisíveis, tais como quedas, fraturas ósseas de proporções sérias, danos irreparáveis ao equipamento e até mesmo mortes. Apesar dessas evidentes possibilidades, o risco parece ser um dos principais aspectos da coesão que se processa entre os indivíduos que vivenciam uma espécie de solidariedade errante que, segundo Duvignaud (1986), não é natural, constituindo-se de participação espontânea e intensa dos homens. Para o autor, tal solidariedade, em nosso caso, entre grupos de voadores permite a possibilidade de reunir indivíduos de diferentes condições, num momento de intensa comunicação. Momentos passageiros e perecíveis, porém muito 
intensos. Essa união de trocas gratuitas e de buscas de prazer através da solidariedade errante, na perspectiva de Duvignaud (1986), forma grupos cujo único laço é a expectativa comum de uma possibilidade que altere as combinações estabelecidas no quotidiano. Tratase de solidariedades que produzem sonhos, atitudes e expectativas que, aos poucos, modificam a imagem na vida coletiva desses homens que praticam tais atividades, tornando-os mais coesos e solidários.

Além do risco, aspectos como habilidade, experiência e praticidade de manuseio também podem ser determinantes para o processo de coesão das comunidades que se formam neste contexto.

Pimentel (2006) afirma que habilidades motoras especializadas e controle psicológico não são suficientes para o surgimento de afinidades entre os voadores. Tal situação depende ainda de aspectos como idade, local de residência, afinidades estéticas, tipos de equipamentos entre outros. O mesmo autor acrescenta ainda que a coesão, a afetividade, o sonho e a paixão pelo voo, expressos na fala dos voadores, contribuem para a formação de redes de socialidades, conceito utilizado quando se pretende destacar relações sociais cotidianas que permitem, a partir de comunicação multi-direcional, formar grupos com interesses semelhantes.

O risco, no contexto social, é tido como um gerador de consequências imprevisíveis. No entanto, tal risco pode revelar-se como um elemento positivo e agregador no contexto de determinadas práticas esportivas, como ocorre no voo livre. Spink, Aragaki e Alves (2005) afirmam que as experiências vivenciadas neste tipo de prática esportiva contribuíram para que o risco também adquirisse sentidos de algo que pode gerar consequências positivas.

$\mathrm{Na}$ concepção de Beck (1998), risco é um conceito ambíguo onde o mesmo é tratado de forma positiva, como nas situações que se tenta através de cálculos se obter um controle do risco, ou de forma negativa, como no caso do risco que se corre nas situações comuns do cotidiano. 
Em busca destes novos sentidos proporcionados pelo risco, atores dos mais variados segmentos sociais - estudantes, advogados, médicos, professores, militares, empresários, entre outros -, de posse de seus valiosos brinquedos voadores, passam a fazer parte do seleto grupo dos seres alados, onde encontram a possibilidade de vivenciar, de forma lúdica, momentos de prazer, repletos de emoções, incertezas e angústias.

No transcorrer desta trilha, encontramos voadores de parapente e de asa-delta que, diante das possibilidades de risco oferecidas pelo ambiente aéreo, formam diferentes comunidades. Dentre estas, podemos destacar a comunidade dos que buscam condições de voo mais arriscadas, destacando-se pela escolha de equipamentos elaborados para a realização de voos mais performáticos, e a comunidade dos que preferem condições de voo menos arriscadas, por isso escolhendo equipamentos elaborados para voos menos performáticos.

Algumas características influenciam de forma direta a escolha da modalidade de voo e, por consequência, a formação das comunidades. Uma destas características diz respeito à diferença que existe entre uma asa-delta e um parapente. Tal diferença pode ser notada comparando-se a posição que o piloto ocupa durante o voo, o desempenho que o equipamento alcança e as sensações percebidas por cada indivíduo durante a prática.

O voo de uma asa-delta é realizado com o piloto deitado na posição decúbito ventral, dentro de uma espécie de casulo posicionado bem próximo à vela. No caso do parapente, o piloto voa sentado em uma espécie de cadeira pendurada distante do velame (tecido que forma a asa do parapente). Em princípio, as sensações provocadas por cada um desses equipamentos vão estar diretamente relacionadas à percepção que o voador tem da dimensão aérea. No caso do parapente, essa percepção será bem maior que aquela que se tem em uma asa-delta, fato que se deve à posição ereta da cabeça e à distância existente entre o velame e o corpo do piloto; estas características aumentam consideravelmente o campo visual, no entanto, expõem o piloto a movimentos pendulares, que por consequência, podem ocasionar indesejáveis e perigosos colapsos 
do velame. Quando o assunto é desempenho, a asa-delta se destaca em relação ao parapente. Pode-se dizer que a posição do piloto, deitado e próximo da asa, contribui para que a mesma tenha uma aerodinâmica bem mais eficiente. As sensações proporcionadas pelo voo de uma asa delta, que atinge velocidades acima dos $100 \mathrm{~km} / \mathrm{h}$, podendo percorrer distâncias superiores a $700 \mathrm{~km}^{9}$, são bem distintas daquelas proporcionadas pelo voo de um parapente, cuja velocidade máxima fica em torno de $60 \mathrm{~km} / \mathrm{h}$, percorrendo distâncias que ultrapassam os $460 \mathrm{~km}^{10}$.

Quanto à percepção que se tem do risco, os praticantes destas duas modalidades apresentam algumas divergências. Para quem voa de parapente, a velocidade que uma asa-delta imprime é um fator importante, principalmente em voos de longa distância; mas este mesmo fator pode transformar o momento do pouso em uma situação muito mais arriscada do que quando se está voando em uma velocidade bem reduzida, como destaca Frank Brown, adepto da modalidade parapente, em entrevista a Fernandes (2004, p. 9):

Eu sinto falta da velocidade, do planeio e da performance da asa, para poder fazer vôos mais longos. Mas no pouso do parapente, você acaba às vezes entrando em lugares que não entraria nunca de asa na mesma altura. Pouso em qualquer lugar, isso é uma grande vantagem.

Por outro lado, quem voa em asa-delta acredita que, pelo fato de não possuir uma estrutura rígida, o parapente é que oferece maiores possibilidades de risco, principalmente em condições turbulentas. É o que afirma André Wolf, praticante da modalidade asa-delta:

[...] eu tenho um medo tremendo de parapente. Acho que os parapentistas não vão gostar de ler isso, mais eu acho totalmente inseguro, exatamente pela falta de estrutura. Os parapentes antigamente começaram a voar em vôos calmos, aí passaram a ficar mais ousados, resolveram voar em qualquer lugar.

\footnotetext{
${ }^{9}$ Recorde obtido pelo austríaco Manfred Ruhmer e homologado pela Fédération Aéronautique Internationale (FAl) em 17/07/2001, na localidade de Zapata (USA).

${ }^{10}$ Recorde obtido pelos brasileiros Marcelo Prieto, Frank Thomas Brown e Rafael Monteiro Saladini em um único voo, realizado em Quixadá (Nordeste brasileiro) no dia 14/11/2007. (FAl)
} 
Mas na minha opinião, parapente não é pra voar em qualquer lugar, tipos Owens Valley ou qualquer lugar mais turbulento. Brasília mesmo, aqui no Brasil, não é condição para um parapente, realmente não é. Eles fecham, infelizmente a gente entra numa turbulência, toma aquela pauleira toda, mas a asa continua voando, parapente fecha. Tudo bem, reabre, tem maneira de abrir, mas ainda assim eu acho muito inseguro. Eu não voaria parapente, teria muito medo de voar parapente. (Entrevista a FERNANDES, 1998, p. 30)

Preferências, gostos e tensões à parte, os discursos dos voadores vão alimentando a concorrência entre asa-delta e parapente, o que contribui de forma significativa para a formação de diferentes comunidades.

Quando são avaliados aspectos como risco, praticidade e performance, na perspectiva destas duas modalidades, novos pontos de divergência podem ser apontados. Com relação à aerodinâmica, como foi visto, pode-se afirmar que o voo de uma asa-delta se destaca quando comparado ao voo de um parapente. Além de desenvolver uma maior velocidade, em condições turbulentas a asadelta comporta-se de maneira mais estável, situação que, para alguns, pode ser traduzida como uma sensação maior de segurança. A possibilidade de uma melhor performance e de um controle maior das situações de risco durante o voo faz com que a asa-delta, mesmo não sendo tão prática quanto o parapente, continue sendo a modalidade preferida de determinados indivíduos. Estes, quando questionados sobre a possibilidade de voarem de parapente, são categóricos em afirmar que não praticam esta modalidade por considerarem que as variáveis de risco que ela apresenta não permitem um controle efetivo.

Ainda dou os meus vôozinhos de lazer por aí, num lift ou num dia de termal fraco mas a questão crucial é uma só: (no parapente) não se tem controle total em certas situações. Não se tem o controle total em termos de comando e reação como numa asa. Já passei por alguns colapsos animais e a sensação 
pra quem voa de asa, é muito esquisita. Agora, é delicioso centrar numa térmica de parapente, te digo até curto mais rodar na térmica de parapa (parapente) do que de asa. E tem aquele astral do cross country - pousou, enrola tudo num saco e vai embora. Apesar disso, na asa tudo é muito mais legal, é mais velocidade, é mais segurança... a finalização de um pouso de asa é uma coisa linda! (Beto Schmitz. Entrevista a FERNANDES, 2000, p. 25)

Acho o parapa (parapente) ótimo para um vôo de litoral. No interior pode te dar milhões de sustos, especialmente em equipamentos de alta performance. $\mathrm{Na}$ asa, se você voa bem, se você domina o equipamento, a sua probabilidade de sofrer um acidente é bem menor. (Luiz Niemeyer. Entrevista a FERNANDES, 2006, p. 10)

A praticidade e a possibilidade de pousar com mais segurança são aspectos determinantes na escolha do parapente. Quando comparado com a asa-delta, o parapente revela-se muito mais prático. Por não possuir estrutura metálica, ele é bem mais leve, proporcionando maior eficiência na montagem, desmontagem e, principalmente, no transporte. Além disso, a velocidade de aproximação do parapente, na ocasião do pouso, é bem menor que a de uma asadelta, tornando mais fácil e seguro o inevitável retorno ao solo, principalmente em lugares onde as possibilidades de pouso são menores. Estes aspectos contribuíram para que muitos pilotos, que até então voavam de asa-delta, se rendessem aos encantos do parapente.

Voava de asa delta porque era o jeito mais fácil e simples que existia de voar. Bastava chegar no alto do morro, montar e decolar. Depois de seis anos voando de asa apareceram os primeiros paracas. A performance era sofrível, mas venciam no quesito simplicidade. Um dia, o Rui Marra, que tinha conquistado o título de campeão brasileiro, apareceu na Moeda, montou uma turma, começou a dar instrução e me formei piloto de parapente. Tentei conciliar a asa e o paraca por mais um ano, voando asa em condições fortes e de paraca na calmaria. Com o tempo fui me acostumando a voar com o paraca em

Wovimento, Porto Alegre, v. 16, n. 03, p. 259-278, julho/setembro de 2010. 
condições mais fortes, até chegar à conclusão de que não poderia voar bem nenhum dos dois se não me dedicasse exclusivamente a um deles [...] (Lucas Machado. Entrevista, a POPPE, 1999, p. 22)

Eu ainda tenho uma asa delta, mas nunca vôo nela. Eu acho tão mais fácil pegar um parapente e voar... asa dá muito trabalho, mas de qualquer maneira, algumas de minhas melhores experiências de vôo foram com uma asa delta, e me incita a voltar a ela de tempos em tempos. (Jhon Pendry. Entrevista a FERNANDES, 1999a, p. 30)

O fato de um parapente poder ser compactado e acondicionado dentro de uma mochila permite que o mesmo seja transportado com mais facilidade. Diferente de uma asa-delta que para ser transportada exige adaptações no veículo, como a utilização de um rack, o parapente pode ser transportado no porta-malas de qualquer veículo de passeio, em uma motocicleta ou até mesmo por uma pessoa, durante uma caminhada.

O parapente entrou na minha vida dez anos depois. Eu estava meio desanimado da asa porque não tinha carro. E não conseguia ter a minha asa, não conseguia viajar. Aí apareceu aquela mochila, eu conseguia ir pra todo canto com aquele negócio, era mais fácil conseguir carona. (Frank Brown. Entrevista a FERNANDES, 2004, p.8)

Depoimentos como estes indicam uma importante contribuição do fator financeiro no aumento do número de praticantes da modalidade parapente. Além de novos adeptos, tal fator é responsável por atrair também um número cada vez maior de pilotos da modalidade asa- delta. Vale ressaltar que a escolha da modalidade de voo leva em consideração os valores investidos na manutenção regular e segura dessa prática. Sem levar em conta os acessórios necessários ou obrigatórios para a prática deste esporte (cinto, selete, paraquedas reserva, variômetro, GPS, capacete etc.), uma asa-delta custa em média o dobro do preço de um parapente e, dependendo do tipo de performance que ela proporciona, pode custar até o triplo. 
Além destes aspectos, existem casos em que as comunidades de voo se formam a partir da habilidade e da experiência acumulada durante a prática. É o caso de pilotos que alcançam um alto nível técnico por estarem acostumados a voar em diferentes lugares, participando de competições. Além do alto grau de confiança, estes pilotos adquirem maior sensibilidade durante $\mathrm{o}$ voo, passando a identificar com mais facilidade a melhor hora para a decolagem, assim como os locais onde se formam as melhores térmicas do dia, como destaca o experiente piloto Tomaz Suchanek em entrevista a Fernandes (1997, p. 13):

De qualquer forma, eu sinto a térmica. Uso o variômetro para confirmar o que sinto, mas ele não é realmente necessário na maioria dos casos. Abaixo de 500 metros, eu posso detectar visualmente minha ascensão. Acima disso, uso outras referências, como outros pilotos, pássaros, nuvens, etc. Desenvolver um feeling no ar desligando seus instrumentos é uma prática muito útil.

A sensibilidade que os indivíduos adquirem em situações como esta é parte integrante de um processo multissensorial, um senso comum (ALMEIDA, 2008) no qual estão envolvidos sons, tatos, odores, distância, velocidade, temperatura, entre outras sensações conhecidas e dominadas no decorrer da vivência de suas práticas. $\mathrm{O}$ autor afirma que, quando experimentadas de modo conjunto, essas sensações darão origem às redomas sensoriais, estas podendo ser ordinárias, como em situações corriqueiras, ou extraordinárias, como é o caso do risco de voar, atividade que para o ser humano corresponde a uma forma de desafiar os limites de seus sentidos ordinários.

No cotidiano da prática do voo livre encontramos voadores de asa-delta e de parapente compartilhando espaços como rampa de decolagem, térmicas, lifts ${ }^{11}$ e pouso. Mais do que compartilhar os mesmos espaços, o ato de voar livre pelos ares está relacionado a aspectos que podem ser importantes para a compreensão dos

\footnotetext{
${ }^{11}$ Área de uma montanha onde predominam os ventos ascendentes. O lift se encontra do lado da montanha em que o vento está soprando (LOPES et al, 2002).
}

Movimento, Porto Alegre, v. 16, n. 03, p. 259-278, julho/setembro de 2010. 
motivos que levariam um indivíduo a adotar um determinado estilo de voo em detrimento de outro. Assim, aspectos como risco e prazer, por possuírem uma relação direta entre si, se tornam peças fundamentais no processo de escolha do estilo mais adequado a cada indivíduo.

Diante desta perspectiva, o prazer de voar poderá ser maior ou menor, dependendo da intensidade do risco e do gosto do praticante. Ou seja, situações que parecem ser extremamente arriscadas podem ser essenciais para o prazer daqueles cuja motivação se encontra no desafio de limites, na realização de voos em condições adversas, como destaca o piloto de asa-delta Mark Gibson em entrevista a Fernandes (1999b, p. 10):

Em Andradas teve um momento em que fiquei muito baixo, em cima de uma área que só tinha árvores, e vi uma bolhinha (térmica fraca) saindo de cima de linhas de alta tensão, aí pensei: ah, que divertido, uma térmica, é lá mesmo que eu vou [...] Às vezes, eu tinha maus sonhos depois desses vôos brabos eu poderia não ter sobrevivido a isto. Mas agora eu sei que nunca sobreviveria se me sentisse entediado como nas condições fracas. Eu gosto de ser sugado pelas nuvens, gosto de térmicas fortes.

A experiência vivida por este esportista está alinhada com a vertigem preconizada por Quinodoz (1995), quando esta aponta a existência de indivíduos que buscam situações de risco e sentem um prazer especial em provocar calafrios em seus corpos, uma espécie de vertigem que ao contrário das demais, não causa angústia.

Seguindo uma linha menos ousada, podemos encontrar indivíduos que também buscam um prazer diferenciado, no entanto, escolhem uma via mais contemplativa onde privilegiam situações menos arriscadas, com poucas, ou nenhuma possibilidade de angústia.

Abdalad (2004) destaca a existência de aventureiros voadores que, na busca de prazer, estabelecem uma espécie de comunhão com a natureza onde o principal objetivo é amenizar o excesso de seriedade e regras vivenciadas no cotidiano social. É o caso dos praticantes que buscam prazer voando em situações menos arriscadas. 
Estou voando há uns dois anos e pouco e é só pro MEU prazer! Já experimentei um pouco de tudo no vôo e hoje escolhi o que me agrada: voar de manhã cedo ou no finalzinho da tarde, vento não mais de 15 , poucas passadas (se é que alguma...) próximas ao relevo (considero meio duro pra ficar passando perto), e, em especial, apreciar bem toda a paisagem. Só enrosco em termais se for pra sair de roubadas, para tentar chegar a um pouso mais longe, não gosto de fazer aproximação a menos de uns $150 / 200 \mathrm{~m}$ do chão, etc, etc. Às vezes sinto que gente como eu é discriminada, mas como disse, o prazer é MEU, então EU escolho como desfrutálo. (LOPES et al, 2002, p. 23)

Independente da maneira como cada indivíduo se comporta diante das diferentes possibilidades de risco, o objetivo principal será sempre a busca do prazer através dos momentos de ludicidade que esta prática oferece. Vale ressaltar ainda que, independente do tipo de voo escolhido, a prática regular, a aquisição de conhecimentos teóricos e a troca de experiências entre os pilotos são aspectos fundamentais para a segurança, para a realização de bons voos e para a manutenção de uma vivência lúdica.

\section{CONSIDERAÇÕES FINAIS}

Considerando-se a variabilidade dos equipamentos, os acessórios tecnológicos, a habilidade, a experiência dos atores e a disposição demonstrada por estes no enfrentamento das adversidades que o ambiente aéreo proporciona, identificamos duas comunidades nas práticas do voo livre. Uma, composta por indivíduos que revelam um grau maior de prazer quando as experiências durante o voo são menos arriscadas, como aquelas realizadas em locais onde as atividades térmicas são mais moderadas e as possibilidades de pouso abundantes; e outra, que elege as experiências arriscadas como fundamentais para a obtenção do prazer, como é o caso daqueles que voam em locais de grandes atividades térmicas e com pouca ou nenhuma possibilidade de pouso. 
A primeira comunidade valoriza acima de tudo o aspecto segurança, que, para ser alcançada, exige a utilização de equipamentos menos performáticos, além de voos em locais onde as condições se apresentam mais tranquilas. Uma das características desta comunidade reside no fato de que seus membros conseguem obter prazer em situações comuns, como subir até o ponto máximo de uma térmica, ou simplesmente decolar, voar por alguns minutos e pousar com segurança.

A segunda comunidade é composta por indivíduos que privilegiam a busca incessante de recordes e as acirradas disputas de campeonatos. Em decorrência do grande número de experiências vivenciadas e compartilhadas nestes ambientes, estes indivíduos, quando comparados aos demais, apresentam maiores possibilidades de ampliar suas habilidades, atingindo um alto nível técnico de pilotagem e maior gerenciamento dos riscos envolvidos na prática em questão. Entretanto, em muitos casos, a obrigatoriedade, a imposição de regras e o excesso de seriedade vivenciados nestes eventos se manifestam contrários ao espírito de liberdade, diminuindo as possibilidades lúdicas que poderiam existir no ato de voar. Na tentativa de satisfazer seus impulsos lúdicos, estes indivíduos incorporam a seus momentos de lazer um sentido de aventura que os impulsiona a locais nunca antes voados. O domínio de tecnologias e de habilidades adquiridas nos campeonatos faz com que os atores que vivenciam esta prática sintam-se tentados a buscar novos desafios que possam lhes proporcionar prazer. Assim, ousam em travessias por locais com pouca possibilidade de pouso, voam em locais desconhecidos em condições impensáveis para pilotos inexperientes ou que não queiram expor-se a riscos de proporções incalculáveis.

Um capital social se instaura entre essas comunidades, fazendo com que os laços de confiança se acentuem, a ação coletiva se reforce, as normas de convivência se tornem possíveis e sentimentos como os de pertencimento e solidariedade sejam desencadeados entre os atores. Tal solidariedade se destaca por ser momentânea; ela surge e agrupa os indivíduos, independentemente de suas condições, como destaca Duvignaud (1986). No voo livre, esse tipo de 
solidariedade pode ser observado na carona oferecida para o acesso à rampa de decolagem, na checagem dos equipamentos e na análise das condições climáticas nos momentos que precedem a decolagem, durante o voo propriamente dito e no resgate do equipamento e do piloto após o pouso.

Considerando-se o nível de coesão que se processa entre aqueles que compartilham o voo, o ambiente regrado e repleto de desafios dos campeonatos, ou ainda a segurança dos voos realizados em condições climáticas mais estáveis, podemos destacar que o risco é elemento fundamental na formação das comunidades que transitam no voo livre. Para Almeida (2008), o risco é um elemento gerador de comunhão e solidariedade coletiva que acentua o sentido de coesão social. É essa coesão social que vincula o mecanismo de integração, de pertencimento e inclusão dos indivíduos dentro de cada comunidade. Tal coesão contribui para que indivíduos que enfrentam juntos os mesmos riscos se percebam como pessoas que professam valores semelhantes.

\begin{tabular}{l} 
The influence of the risk-adventure process of \\
cohesion of different communities of the free \\
flight \\
Abstract: The aim of this study was to investigate \\
the sense of risk as a generating element of communion \\
among the free flight practitioners. We analyzed 10 \\
reports, published in the magazines Air Time Adventure \\
and Sky News, and in the book Parapente Brasil. This \\
is an exploratory research with a qualitative approach. \\
From these speeches, we analyzed the aspects which \\
contribute to the process of cohesion experienced in \\
their daily practice. We realized that risk is a funda- \\
mental element in the formation of communities of flight. \\
Allowing the ones who face together the same risks \\
that they notice each other as people who profess \\
similar values. \\
Keywords: Free flight. Risk-taking. Social values. \\
\hline
\end{tabular}

Movimento, Porto Alegre, v. 16, n. 03, p. 259-278, julho/setembro de 2010. 


\begin{tabular}{l}
\hline La influencia del riesgo-aventura en el proceso \\
de cohesión de las diferentes comunidades de \\
vuelo libre \\
Resumen: El objetivo del estudio fue investigar los \\
sentidos del riesgo como elemento generador de \\
comunión entre practicantes de vuelo libre. Para eso, \\
recurrimos a una investigación exploratoria con \\
abordaje cualitativa, donde fueron abordados aspec- \\
tos del vuelo relacionados al riesgo aventura como \\
tema principal. Partiendo de los discursos de los \\
voladores, analizamos los aspectos que contribuyen \\
para el proceso de cohesión vivido en el prácticas \\
cotidianas. Así, constatamos que el riesgo es un ele- \\
mento fundamental en la formación de las comunida- \\
des de vuelo, posibilitando que individuos que \\
enfrentan juntos los mismos riesgos se vean como \\
personas que profesan valores semejantes. \\
Palabras-clave: Vuelo libre. Assunción de riesgos. \\
Valores sociales.
\end{tabular}

\section{REFERÊNCIAS}

$A B D A L A D, L$. A participação feminina nos esportes de aventura e risco: um vôo no universo do desafio e da incerteza. 2001. Dissertação (Mestrado em Educação Física e Cultura) - Programa de Pós-graduação em Educação Física, Universidade Gama Filho, Rio de Janeiro, 2001.

ALMEIDA, Luiz Guilherme Veiga de. Ritual, risco e arte circense: o homem em situações limites. Brasília: UNB, 2008.

AZEVEDO, Sergio L. Gomes; COSTA, Vera Lúcia de Menezes. A aventura humana de voar por esporte. In: VARGAS, Ângelo; PIMENTEL, Fabiana; GALVÃO, Ana Lília O. (Org.) Esportes: polêmicas de nosso tempo. Rio de Janeiro: Câmara Municipal do Rio de Janeiro. 2008. p. 19-25.

BARDIN, L. Análise de conteúdo. Lisboa: Edições 70, 2004.

BAUER, Martin W.; GASKEL, George. Pesquisa qualitativa com texto, imagem e som: um manual prático. 5. ed. Petrópolis: Vozes, 2002.

BECK, Ulrich. Risk Society: towards a new modernity. Cambridge, UK: Polity Press, 1998.

BECKER, H. S. Métodos de pesquisa em ciências sociais. São Paulo: Hucitec, 1994. 
CAILLOIS, R. Os jogos e os homens: a máscara e a vertigem. Lisboa: Cotovia, 1990.

COSTA, Vera Lucia de Menezes. Esportes de aventura e risco na montanha: um mergulho no imaginário. São Paulo: Manole, 2000.

DRACON. In: Dicionário Náutico. Porto Alegre: Piccolo Sails, 2009. Disponível em: < h t t p : / / w w w. p i c c ol os a i ls. com . br/d i c i o n a r i onautico_result.asp?trm=Dacron\&selecao=47 . Acesso em: 4 ago. 2009.

DUVIGNAUD, J. A solidariedade: laços de sangue, laços de razão. Lisboa: Instituto Piaget, 1986.

FAI - Fédération Aéronautique Internationale. Disponível em: http://records.fai.org / hang_gliding/current.asp?id1=81\&id2=1 (s.d.). Acesso em: 15 maio 2009.

FERNANDES, P. C. Entrevista: Tomaz Suchanek. Air Time, Rio de Janeiro, p. 13, 1997.

Entrevista: Mark Gibson. Air Time, Rio de Janeiro, p. 10, $1999 b$.

Entrevista: Beto Schmitz Bicho de Nuvem. Air Time, Rio de Janeiro, n. 24, p. $25,2000$.

Entrevista: Frank Brown. Air Time, Rio de Janeiro, n. 9, p. 9, 2004.

Entrevista: Os irmãos Niemeyer. Air Time, Rio de Janeiro, n. 13, p. 10, 2006.

Entrevista: Robbie Whintall e Jhon Pendry. Air Time, Rio de Janeiro, n. 20, p. 30, 1999a.

GIDDENS, A. Modernidade e identidade. Rio de Janeiro: Zahar, 2002.

LOPES, R. S. et al. Parapente Brasil: histórias e aventuras do vôo livre. Rio de Janeiro: Editado por Rodrigo Stulzer Lopes, 2002.

MAFFESOLI, M. Os tempos das tribos: o declínio do individualismo nas sociedades de massa. 3. ed. Rio de Janeiro: Forense, 2000.

PIMENTEL, Giuliano Gomes de Assis. Risco, corpo e socialidade no Voo livre. Tese (Doutorado em Educação Física) - Faculdade de Educação Física, Universidade Estadual de Campinas, Campinas, SP, 2006.

POPPE, M. Entrevista: Lucas Machado. Air Time, Rio de Janeiro, p. 22, 1999.

QUINODOZ, D. A vertigem: entre a angústia e o prazer. Porto Alegre: Artes Médicas, 1995.

SPINK, Mary Jane P.; ARAGAKI, Sérgio Seiji; ALVES, Marina Pigozzi. Da exacerbação dos sentidos no encontro com a natureza: contrastando esportes radicais e 
turismo de aventura. Psicologia: Reflexão e Crítica, Porto Alegre, v..18, n. 1, p. 2638, abr. 2005.

MOSQUETÃO. In: WIKIPÉDIA. Disponível em: <http://pt.wikipedia.org/wiki/ Mosquet\%C3\%A3o_(pe\%C3\%A7a_met\%C3\%A1lica)>. Acesso em: 4 ago. 2009. 